\title{
Forest Strategy in Republic of Macedonia: Barriers to Effective Implementation
}

\author{
Jana Baumgartner ${ }^{1}$, Makedonka Stojanovska $^{2}$
}

\footnotetext{
${ }^{1}$ MSc Forest Policy and Economics, FOPER Master Program, Ss. Cyril and Methodius University in Skopje, Faculty of Forestry, Aleksandar Makedonski bb, MK-1000 Skopje, Republic of Macedonia

2 Ss. Cyril and Methodius University in Skopje, Faculty of Forestry, Aleksandar Makedonski bb, MK-1000 Skopje, Republic of Macedonia

${ }^{\vee}$ Corresponding author: e-mail: jana.baumgartner@icloud.com
}

\section{Citation:}

BAUMGARTNER J, STOJANOVSKA M 2014 Forest Strategy in Republic of Macedonia: Barriers to Effective Implementation. South-east Eur for 5 (1): 23-33. DOI: http://dx.doi.org/10.15177/seefor.14-03

\section{Abstract}

Background and Purpose: In recent years, implementation of forest strategies and programs has been acknowledged as an important phase of the forest policy process. Forest policies such as conflict management concepts between deferent interests of stakeholders, are a dynamic route that needs to be managed carefully to achieve its goals. Creation of the forest policy document entitled "Strategy for sustainable development of forestry in Republic of Macedonia" was introduced for the first time in 2005 as cooperation between the Government and United Nations Food and Agriculture Organization (FAO). Action Plan was brought in the same year including the strategy and validity until the end of the year 2009 now is out of date for undetermined reasons, due to lack of analysis of the level of implementation, monitoring and evaluation.

Materials and Methods: Through exploratory qualitative method using a case study, this paper attempts to explore different stakeholders perception of the most common barriers for implementation of the Strategy for sustainable development of forests in Republic of Macedonia and ascertain if implementation variables are identified as barriers in the implementation stage.

Results: The research showed that environmental and organisational barriers such as legal restrictions, political willingness, social change, control, leadership and clear responsibility are the most common barriers impeding forest strategy implementation in Macedonia.

Conclusions: The paper concluded that the three year action plan was too ambitious, given the existing human and technical capacities in the forestry sector, recommending participation of all included stakeholders in the implementation as an important fact in overcoming the current barriers and moving forward the process.

Keywords: forest strategy, implementation barriers, organizational structure, environment, change management 


\section{INTRODUCTION}

Strategic management consists of the analysis, decisions, and actions an organization undertakes in order to create and sustain competitive advantages [1].

The study of strategic management is concerned with the relationship between an organisation and its environment in order to be successful $[2,3]$. However, the strategies will not benefit organisations unless implemented successfully [4]. Although the importance of strategy implementation is widely acknowledged, strategy implementation remains a process, which is poorly understood [4].

Creation of the forest policy document in Macedonia was introduced for the first time in 2005 as cooperation between the Government and the Food and Agriculture Organisation of the United Nations (FAO). The process started with a project entitled "Institutional development and capacity building in forestry and forest industry subsectors" for duration of one year resulting in a document named "Strategy for sustainable development of forestry in the Republic of Macedonia" with Action Plan. Following the course where national forest policy facilitates communication, coordination and collaboration across government, nongovernmental organisations and the public [5], the formulation process was assessed as open, participatory and transparent by all parties included, in as much as "mutually accepted forest policy builds a sense of joint ownership, which is essential for its implementation" [5].

Social and political changes in the Republic of Macedonia brought by shifting from centrally oriented to market economy in a relatively young democracy along with Governmental aspirations for European Union integration, inevitably required addressing priorities and responding to new realities. The Strategy reflects forestry described needs of all stakeholders, in line with national development, environmental action plans and
European Union standards, and serves as a guideline on how to sustainably conserve and manage forest resources for their contribution in the society.

Action Plan brought in the same year with the Strategy and valid until the end of the year 2009 is now out of date and its implementation stage is unknown due to lack of analysis of the level of implementation, presence of neither monitoring nor evaluation. Shifts in social and demographic trends, along with changes in economic, environmental, technological and political contexts, inevitably require that policy respond to new realities, risks and opportunities [5].

The terms "policy" and "strategy" are frequently used interchangeably [5]. Certain countries use the term "strategy" to specify forest policies, and others "national forest programs" to define strategic base for forest policy. In countries in the South Eastern Europe region, (for example in Serbia, Croatia, Montenegro, Bulgaria, Albania), national forest programs, and forest policies or in some cases named strategies, are developed. However, analysis of the level of implementation or effectiveness is lacking. The reasons are unknown and insufficiently researched.

Through the research question "What are the barriers that impeded effective Forest Strategy implementation in Republic of Macedonia?" this paper will explore different stakeholders perception of the most common barriers for implementation of the Strategy for sustainable development of forests in Republic of Macedonia and ascertain if implementation variables are identified as barriers in the implementation stage. The implementation process is one of the most important aspects of strategic management because "effective strategies are of no value if they are not properly executed" [1].

Implementation stage is important and considered as one of the instruments to achieve the goals prescribed in the formulation part of the Strategy. Even though all three stages of the strategic process (analysis, 
formulation and implementation) are equally important, scientific literature [6] showed that the implementation stage is least researched and explored.

\section{MATERIALS AND METHODS}

The focus of this paper is exploratory, based on existing studies done in the area of strategy implementation. As this research intends to explore the area of strategy implementation where there appear to be an inadequate understanding of the phenomena [7], qualitative method is a suitable approach for it.

Case studies are exploratory [8] and may also be developed to explain, in comprehensive detail, how or why a particular phenomenon came into being [8]. Yin [9] defines a case study as an "empirical enquiry that investigates a contemporary phenomenon within its reallife context; when the boundaries between phenomenon and context are not clearly evident; and in which multiple sources of evidence are used".

Therefore, a case study of the implementation of the Strategy for forestry in Macedonia was prepared to answer the research question by gathering, from multiple sources and methods, as much data as possible of the phenomena being researched.

\section{Triangulation}

In social science research, the inclusion of multiple perspectives (i.e. triangulation) contributes to achieving a more comprehensive and accurate accounting of the issue under investigation.

Triangulation can be accomplished through utilizing multiple methodologies (thereby employing both deductive and in-ductive reasoning) (e.g., telephone survey and key informant interviews), datasets (e.g., census data and historical records), observers from varied perspectives, and / or analysis at multiple scales (e.g., individual, group, region) [8].

In order to enhance confidence of the research findings, the research employs literature review, conducting semi structured interviews and secondary data analysis. The review of scholarly articles in the field of strategic and policy implementation provided the theoretical and conceptual framework and aided the formulation of the research question.

A questionnaire was assembled and semi-structured interviews with open-ended questions were conducted with the identified stakeholders. Secondary data source were compared with the results and provided validations for the research.

\section{Semi Structured Interviews}

The process involved identifying key individuals and involving them in structured exercises designed to elicit their views on the researched topic.

Intended research sample was found with all parties included in the process of creation and implementation of the Strategy, such as governmental bodies, research institutions, nongovernmental sector, public enterprises, national parks etc. (heads of units, middle management and top level management).

The questionnaire for the interview was designed to answer the research question - to identify the barriers for successful Strategy's implementation.

Interviews were conducted with nine members of the projects' Steering Committee and Working Group at the time of formulation of the Strategy. All participants are employed in different forestry and forestry related institutions or projects, and are on different management level in the respective organisations. Several of them were also included in the implementation stage of the Strategy. Table 1 provides list of interviewees' professional background and working institution.

After the ninth interview, no new information appeared therefore, in order to avoid repetition; the researcher concluded the process of gathering data (saturation principle). The interviews were anonymous, and coded names were used for each participant. 


\section{Secondary Data}

In addition to interviews, secondary data were another source of data used for this research. Internal data such as different documents, emails, presentations, minutes from meetings and workshops, implementation documents, etc. presented source for analysing from the period of the formulation process. Most of these data were found in the former project office (FAO Office) and the Ministry for Agriculture, Forestry and Water Management, Department for Forestry as implementing body of the project.

Total of forty-six documents in form of reports, minutes and presentations in the process of formulation of the Strategy were considered in the method of secondary data analysis.

\section{Specific Methods for Data Analysis}

During the interviews, notes were made, recording observations and thoughts on each of the interviews. After each interview, a transcript of the interview was typed and specific dates were set. These transcripts were then converted into text files so that a computer program MaxQDA could process them. MaxQDA is a type of Qualitative Data Analysis software that supports all individuals performing qualitative data or content analysis by helping to systematically evaluate and interpret textual data. As the secondary data were found in text files form, the MaxQDA software was also used for analysis.

The data were organised using an objective coding scheme. Each code was assigned to selected segments of text. Codes and sub codes were ordered into a hierarchical structure for better visualisation.

\section{THEORETICAL BACKGROUND}

\section{Strategy Implementation Framework}

Strategy implementation is defined as the communication, interpretation, adoption, and enactment of strategic plans [10]. Analysing the literature in the field of strategy implementation, Yang Li et al [6] define strategy implementation as a dynamic, iterative and complex process, which is comprised of a series of decisions and activities by managers and employees affected by a number of interrelated internal and external factors to turn strategic plans into reality in order to achieve strategic objectives.

Policies that work in practice need to be designed with implementation in mind [5].

TABLE 1. Institution and background of the interviewees

\begin{tabular}{cllc}
\hline Interviewee & \multicolumn{1}{c}{ Institution } & \multicolumn{1}{c}{ Background } & $\begin{array}{c}\text { Date of the } \\
\text { interview }\end{array}$ \\
\hline 1 & International non-Governmental Organisation & Forestry consultant & 27.2 .2012 \\
2 & $\begin{array}{l}\text { Ministry for Agriculture Forestry and Water } \\
\text { Economy }\end{array}$ & Forestry officer & 28.2 .2012 \\
3 & $\begin{array}{l}\text { Ministry for Agriculture Forestry and Water } \\
\text { Economy }\end{array}$ & Forestry officer & 28.2 .2012 \\
4 & Public Enterprise "Macedonian Forests" & Forest & 29.2 .2012 \\
5 & Forestry Faculty & Professor & 2.03 .2012 \\
6 & FAO Project Office & Forestry consultant & 9.03 .2012 \\
7 & FAO Project Office & Forestry consultant & 11.03 .2012 \\
8 & Forestry Faculty & Professor & 13.03 .2012 \\
9 & Forestry Faculty & Professor & 13.03 .2012 \\
\hline
\end{tabular}


This requires agreement on the approach and on responsibilities as well as flexibility on the methods to achieve objectives. It also needs an understanding on funding and on re-aligning legal and institutional frameworks with the new or amended policy [5].

Key authors in the field of strategic management have developed different implementation frameworks. Studies concluded that the most commonly occurring strategy implementation problems among others are: uncontrollable external factors, inadequate leadership and direction by departmental managers, co-ordination of implementation not effective enough and major problems which surfaced that had not been identified earlier [11].

In a study of senior managers six key barriers to strategy implementation are identified: top down or laissez-faire senior management style; unclear strategy and conflicting priorities; an ineffective senior management team; poor vertical communication; poor co-ordination across functions, business or borders; and inadequate down-the-line leadership skills and development [12].

A comprehensive list of implementation frameworks, highlighting significant implementation variables researched by key auth-ors [13] identifies ten common variables: strategy formulation, environmental uncer-tainty, organisational structure, culture, operational planning, communication, resource allocation, people, control and outcome [13]. Researchers have originally been classified these variables into categories such as "content", "context", "process" and "outcome" [13], however, the classifications are not fixed on what is included in which categories. If the variables are important to the success of strategy implementation, and not accomplished well, they could become obstacles to implementation. The frameworks emphasise the continuous interactions among these variables and it is believed that it is these on going interactions, which make implementation possible [13].

The research will take an approach considering that the environmental and orga- nizational structure variables may potentially be barriers to the process of strategy implementation.

Environment as a variable can exist from external or internal nature. If there are significant changes in the environment, reaction is needed if effective implementation of the strategy is a high priority. The implementation process itself makes environment uncertainty and a possible barrier to strategy implementation. Ignorance or inabi-lity to determine and recognise environ-mental changes will possibly lead to strategy's nonperformance in the implementation stage.

Organisational structure is one variable which management can adapt to lead the organisation to its desired goals and objectives [14]. Organisational performance is based on ensuring a fit between strategy and structure. In order for strategy to create superior performance, it must be complemented by appropriate organisational characteristics and employee behaviours. [15].

\section{Change Management}

Due to the lack of literature in strategy implementation, change management theory is useful in providing a theoretical base for this research.

Change to organisations implies persuading people to abandon their existing beliefs and values and the behaviours that stem from them and adopt new ones [16]. There are several aspects in change management [17] and studies of strategic change illustrate its complexity: the political battles, the cultural barriers, the inertia of organisation structures, and systems and the bounded rationality of managers [18]. This complexity and several potential problems associated with the strategy itself, the way it was developed, or the management of the change process makes realising strategy an extremely difficult task [18]. The challenges presented in managing change are very similar to those of implementing strategy.

Lewin's Freeze Phases explains change involving a move from one static state, via 
a state of activity, to another static status quo [19]. All this via a three-stage process of managing change: unfreezing, changing and re- freezing [19].

Kotter's eight-step strategy for change management consists of: establish a sense of urgency; create the guiding coalition; develop a vision and strategy; communicate the change vision; empower employees for broad- based action; generate short-term wins; consolidate gains and produce more change; and anchor new approaches in the culture [20].

The demand for creation of the Forest Strategy in Macedonia and the manner in which was created is derived from a real need for forest policy change which in the case of Macedonia, was externally driven. For example, a participatory approach in decisionmaking process was introduced for the first time. It further introduced new relations, communications and collaboration between involved stakeholders. The document prescribes deliberate course of actions, which needs to be implemented for the purpose of achieving the overall objectives. It also relates to what happens on a local level: the document is worth nothing unless it results in actual change.

\section{RESULTS}

\section{Common Barriers to Strategy Implemen- tation}

In this section, interviewee's findings of barriers of strategy implementation are presented. Participants were asked to identify barriers that in their perspective impede Strategy's implementation in Macedonia. The transcript's software analysis ranked identified barriers based on numbers of codes:

Throughout the analysis, new sub-codes emerged based on responses from the transcripts, specifying each code in more details. The following matrix presents the coding and sub-coding tree with frequencies of presence in interviews analysis. Frequencies of a certain code are presented by square where, the bigger the square is, the bigger the presence of a code or sub code is in the transcripts.

In the following sections, the results of each barrier will be presented together with detailed outcomes of the sub-codes.

\section{Environment}

Most of the participants in this research identified the environment as the biggest barrier in the implementation of the Strategy. Sub codes that the interviewees identified were: legal restriction, political change, political will and social change. Almost all respondents indicated the lack of political willingness for implementation as the greatest barrier for effectiveness.

"The political support and will that existed in the process of formulation, even with the change of the political structure at the beginning of the implementation process in 2006, melted and disappeared in 2007."

Respondents referred to the decision at the end of the process of formulation: the Ministry for Agriculture, Forestry and Water Economy is responsible for Strategy's implementation. As one interviewee explained, this is a Governmental document and it is their responsibility to implement all proclaimed strategic documents. Politics has vast influence, especially in the complex organisational structure such as the Ministry

TABLE 2. Identified barriers based on number of segmented codes in the transcripts

\begin{tabular}{cc}
\hline Identified barrier & $\begin{array}{c}\text { Number of } \\
\text { segmented codes }\end{array}$ \\
\hline Environment & 48 \\
Organisational structure & 48 \\
\hline
\end{tabular}




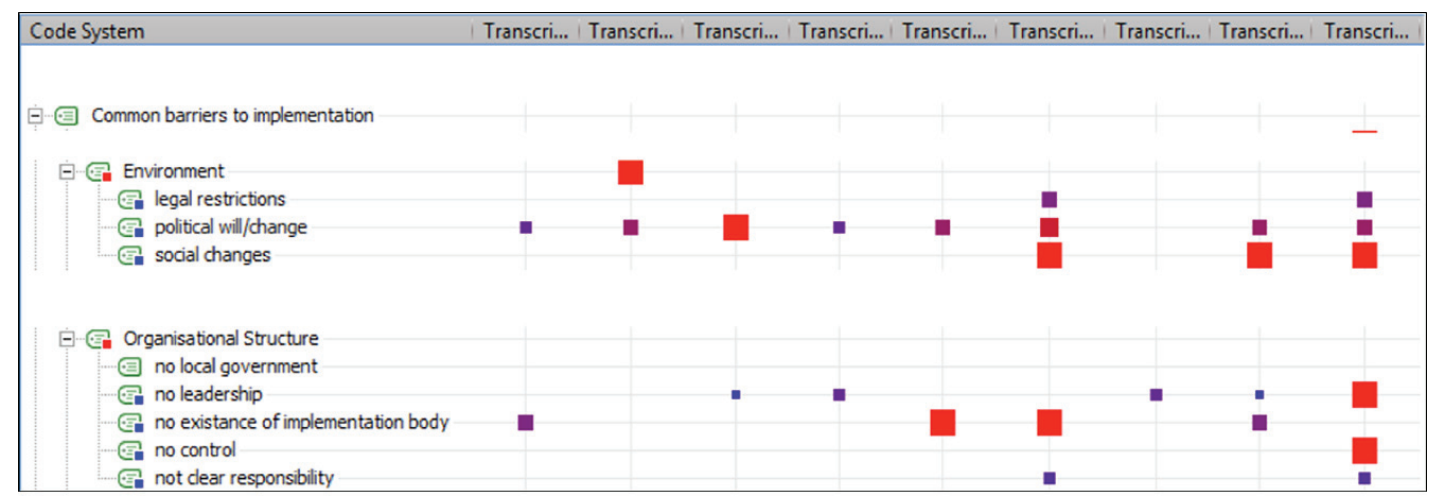

FIGURE 1. Code and sub-code tree with frequencies of presence in the transcripts

for Agriculture, Forestry and Water Economy, where several departments are competing and lobbying to obtain higher segment from the national budget.

"What was planed to be implemented as actions, financed by the state budget, is done. But, what needs external investments is not implemented due to someone's political will." Responsible people are now in a status quoi position, keeping their heads down. There is no control mechanism to react to bad political decisions".

Another important notice is that two months after the Strategy's governmental proclamation, parliamentary elections occurred with change in the political structure. Participants were asked if this change influenced the implementation process however most of the answers were uncertain. Still, they all agreed that the implementation of the Strategy is not on the agenda of the current Government.

Looking at the situation from this perspective, the interviewees highlighted that the previous Governmental structure pushed the proclamation of the Strategy to occur before the elections, for gaining political points. It is a situation where the responsibility over the implementation is lost. The respondents expressed their view that the political influence falls only upon those actions that refers to institutional reforms, such as the transformation of the forest public enterprise and creation of a separate agency for forestry as an independent body in the Government.

Identified as one of the key element for successful formulation, the participants in the formulation-working group were coming from different political parties.

The secondary data analysis showed the political change and legal restrictions to have an influence in the implementation process. Project reports, issued after the official proclamation, stated the expectation to have personnel changes in the head management team after the change of the Government, predicting a period of uncertainty and inactivity of the forestry administration. Also, the position of the National Coordinator of the project, coming from the head of the forestry department in the Ministry was unstable. Hence, an extension of the project was demanded in order to finalise important planned activities such as the Donor Table meeting.

Regarding legal restrictions as a barrier for implementation, participants believed that several changes in the legislation are needed in different sectors, for example in the public procurement. Another view is expressed in the following statement: "The Strategy was proclaimed at the governmental level, and not in the Parliament, therefore it is not legally binding. Fiscal implications are missing for successful implementation".

Likewise, secondary data analysis showed the need of forest legislation revision in several segments for more efficient Strategy 
implementation. To follow the proposed institutional reforms stated in the Strategy, new legal adoption would need to succeed.

The social change, especially in the transition period of the country, also played a part in the implementation. As some of the interviewees explained, over-employment, inadequate qualifications for high positions and political influence for distribution of personnel resulted in negative impacts in the implementation stage.

\section{Organisational Structure}

Additional barrier identified by the participants in this research is the organisational structure with the following sub codes: leadership, formation of the implementation body, control and clear responsibility.

Members of the formulation-working group stated lack of leadership as the most common barrier in the case of implementation stage of the Macedonian Strategy. Non-capability of the leading management structure to assign and delegate tasks or actions was identified as weakness in the implementation process.

"The responsibility is in the management structures, their readiness to respond to challenges and global trends. Coming to the office and signing documents are not the only tasks to be fulfilled, but looking at the situation in a long term perspective should be In their terms of references".

Instead, the need of assigning a high position political person in charge for implementation was identified by several respondents. In the discussion for creating an implementation body it was stated that one of the members has to be a minister or high governmental personnel such as vice prime minister to give higher value of the process.

After finalising the formulation project, the leading project personnel discussed the need to create a separate implementing body with main task, being the implementation of the Strategy according to the three-year action plan. Even though for some interviewees this was not defined as a main barrier, others stated that the ministry rejected this proposal to prioritise other actions, such as the inventory project.
"Another element is a lack of strategy on how to implement the Strategy. Yes, the proposal for creating implementing secretariat was on the table, but the Ministry stated that the priority is to start with the Inventory project rather then to deal with the implementation body. The Ministry set up its priority because at that time the political support for the Strategy was on a very high level and good will existed for the implementation. Nevertheless, the Ministry did not even assign one person who would be responsible for implementation, it was left on the Forestry Department employees to deal with it between their daily tasks. "

Respondents stated that unclear responsibility for implementation led to the current situation. The Strategy and the project documents state that the overall responsibility is in the hands of the Ministry, but other stakeholders also have a role in the implementation. It was lack of assigning responsible institution that created an unclear situation. Additionally, lack of control for non-implementation also facilitated the implementation aside.

In one of the project reports it was mentioned that the current institutional setup caused overlap of responsibilities of the forestry administration with those of other authorities, which could result in potential conflict. Accordingly, the evolution of institutional arrangement should be gradual.

The secondary analysis also showed that lack of delegating tasks from the action plan to the local level government led to failed effectiveness of the Strategy implementation. Reports from participatory workshops showed that local stakeholders asked for more decentralised action plan and greater cooperation with the local population.

\section{DISCUSSION AND CONCLUSSIONS}

This paper is part of a broader research of a master thesis entitled "Factors that impede Forestry Strategy implementation in Republic of Macedonia". One of the reasons for this 
paper and overall of the thesis, was the lack of research in the implementation phase as part of the forest policy process in Macedonia but also in the South Eastern Europe region. The main purpose was not to lead the responsible forestry management team, but rather to create a better understanding of the implementation stage and bring contribution for more efficient and effective results of the Strategy for sustainable development of forestry. Besides, policies tend not to prescribe how goals should be reached, but instead specify expected results - a change that better allows stakeholders to contribute according to their respective means and to adapt the means over time, taking into account experiences and changing contexts [5].

Further on, the analysis of this research did not concentrate on the inner relations between different barriers of implementation. The interaction and interface was obvious during the research and could be studied in further exploration.

All invited persons, except for one, replied to the invitation to participate in this research and gave their views and feelings about the research field. Respondents' interest and support was obvious, followed by their curiosity in the results.

A simple explanation of the findings is that the formulation of the Strategy was very successful, mainly because it was externally driven project. The process had defined time frame, responsibilities and foreign budget. It was first of a kind happening in the forestry department, and therefore it gained high political support.

The formulation of the Strategy introduced new democratic decision- making process in the forestry sector for the first time. The initiated change imposed introduction of new parties working according to governance principals, in a participative and transparent manner, negotiating between each other and resolving conflict situations. However, changing as little as possible, the administrative stakeholder's coalition is focused on keeping the power of future management and decision-making process as it was before the formulation of the Strategy. Reasons could be found in the traditional top down mentality and cultural background of the high-level management team. In this sense, the role of the civil society is still weak and undeveloped. Effective implementation of policies and policy processes requires, first and foremost, synergy between State and citizens [5].

Even though it is not certain if the change of the Government at the beginning of the implementation process was a barrier to the Strategy's implementation, it definitely influenced future development. The new forestry head management team did not received the same political support, as it was the case in the formulation phase. They also faced the problem of re- introduction of the Strategy to the new governmental structure, where higher ranking politicians were not informed about the formulation process.

Another point is that the Strategy is a nonlegally binding document, leaving space for lack of control and low responsibility for not implementing the prescribed goals.

Assigning a high political figure with leadership and communication skills to lead an efficient implementation team, as a separate body in the forestry department, is the missing step for a successful implementation.

The forest policy process in Macedonia does not define the monitoring and evaluation phases of the Strategy. One of the conditions for moving the process forward is establishing regular monitoring, not only as quantitative measurement of implemented actions, but also as a qualitative measurement of effects of change. It is always advisable, even necessary, to monitor implementation and to evaluate whether a policy is achieving the desired outcomes [5]. Therefore, arrangements for monitoring and review should be an integral part of the strategy and any follow- up plan [5]. The evaluation of the past process would give the course in which future direction implementation should follow.

To assess the situation of the Macedonian Strategy, separate and independent body should evaluate the current capacities of the 
forestry staff, the presence of participation of stakeholders, and transparency and accountability in the implementation process. Reasons could be found in the absence of abilities for transparent and non-biased self evaluation unrestricted by political influence. Even though training for open and transparent functioning was conducted in the formulation stage, the traditional way of working and mentality are present. For example, the use of new information and communication technologies, such as online tools are missing in the daily working tasks. In line with this, existence of human and financial capacities for sharing information, such as public relation unit, is lacking. Adaptation to new requirements and changing conditions for Strategy implementation would involve the existence of tools, information and capacities to evaluate head management team self performance in providing information, conducting consultation and engaging stakeholders.

In the preparation and implementation of the policy, it is crucial to make accountability clear - who is responsible for what and the con- sequences of non-performance. It is impor-tant to ensure that responsibilities, authority and accountability are aligned - that people are not held responsible for occurrences over which they have no control, but that they also pay the price if they use their responsibility, authority and resources badly [5].

It is important to realise that all inter-viewees understood the solutions for overco-ming previously identified barriers. This indi-cates that the knowledge to move forward is present but not used. Conclusion from this outcome is that the participation of all the stakeholders included in the implementation is an important fact in overcoming the current barriers and moving the process forward. It is also important to realise that the implementation of the Strategy is a dynamic and vivid process. Changes should be recognised and included, or necessary adaptation should be made to enhance the effectiveness of the prescribed goals. Or as the literature describes: "Implementation is a dynamic process of negotiations between multiple actors, operating at multiple levels, within and between multiple organisations" [21].

\section{REFERENCES}

1. DESS G 2007 Strategic Management: Creating Competitive Advantages. 3rd ed. McGraw-Hill/ Irwin, Boston, USA, pp 7-14

2. CAMILLUS J 1997 Shifting the Strategic Management Paradigm. European Management Journal 15 (1): 1-7. DOI: http://dx.doi.org/10.1016/ $\underline{\text { S0263-2373(96)00068-0 }}$

3. MINTZBERG H, AHLSTRAND B, LAMPEL J 2005 Strategy Safari: A Guided Tour Through The Wilds of Strategic Managament. The Free Press, New York, NY, USA, $404 \mathrm{p}$

4. REID D M 1989 Operationalizing Strategic Planning. Strateg Manage J 10 (6): 553-567. DOI: http://dx.doi.org/10.1002/smj.4250100604

5. FAO 2010 Developing effective forest policy: a guide. Food and Agriculture Organization of the United Nations, Rome, Italy, 69 p. URL: http:// www.fao.org/docrep/013/i1679e/i1679e00.htm (12 February 2014)

6. YANG LI, SUN GUOHUI, MARTIN J 2008 Making Strategy Work: A Literature Review on the Factors Influencing Strategy Implementation. Institute of Corporate Communication, University of Lugano (USI), Lugano, Switzerland, ICA Working Paper 2/2008, 46 p. URL: http://www.knowledgecommunication.org/pdf/making-strategy-work. pdf (5 February 2014)

7. MORSE J, RICHARDS L 2002 ReadMe First: for a User's Guide to Qualitative Methods. Sage Publications Inc., Thousand Oaks, CA, USA, $280 \mathrm{p}$

8. BLISS J C 2010 Asking the Right Questions: Research Objectives, Approach, and Design. Draft Chapter Prepared for Inclusion in Socioeconomic Research Methods in Forestry. Centre for Agriculture and Biosciences International (CABI), London, UK 
9. YIN R K 2003 Case Study Research: Design and Methods. Third Edition, Sage Publications Inc., Thousand Oaks, CA, USA, $160 \mathrm{p}$

10. NOBLE C H 1999 The eclectic roots of strategy implementation research. J Bus Res 45 (2): 119134. DOI: http://dx.doi.org/10.1016/S01482963(97)00231-2

11. ALEXANDER L D 1985 Successfully implementing strategic decisions. Long Range Plann 18 (3): 91-97. DOI: http://dx.doi.org/10.1016/00246301(85)90161-X

12. BEER M, EISENSTAT R A 2000 Overcoming the "silent Killers" to Strategy Implementation and Organizational Learning. Division of Research, Harvard Business School, $28 \mathrm{p}$

13. OKUMUSF 2001 Towards a Strategy Implementation Framework. International Journal of Contemporary Hospitality Management 13 (7): 327-338. DOI: http://dx.doi.org/10.1108/09596110110403712

14. HERACLEOUS L 2003 Strategy and organization: realizing strategic management. Cambridge University Press, Cambridge, UK, 256 p

15. OLSON E M, SLATER S F, HULT G T M 2005 The importance of structure and process to strategy implementation. Bus Horizons 48 (1): 47-54. DOI: http://dx.doi.org/10.1016/j.bushor.2004.10.002
16. SADLER P 2001 The seamless organization: Building the company of tomorrow. Kogan Page Publishers, London, UK, $172 \mathrm{p}$

17. PRYOR M G, TANEJA S, HUMPHREYS J, ANDERSON D, SINGLETON L 2008 Challenges Facing Change Management Theories and Research. Delhi Business Review 9 (1): 1-20

18. PETTIGREW A M, THOMAS H, WHITTINGTON R (eds) 2006 Handbook of strategy and management. Sage Publications Inc., London, UK, 544 p

19. ROBBINS S P 2002 Organizational Behavior. 10th edition, Prentice Hall, Inc., Upper Saddle River, New Jersey, USA, $704 p$

20. CAMERON E, GREEN M 2012 Making Sense of Change Management: a Complete Guide to the Models, Tools, and Techniques of Organizational Change. Third edition, Kogan Page Publishers, London, UK, $502 \mathrm{p}$

21. NAJAM A 1995 Learning from the Literature on Policy Implementation: A Synthesis Perspective. International Institute for Applied Systems Analysis, Laxenburg, Austria, IIASA Working Paper 95-61, 70 p. URL: http://webarchive.iiasa. ac.at/Admin/PUB/Documents/WP-95-061.pdf (18 February 2014) 
